\title{
Analisis Urgensi Kewirausahaan Berbasis Teknologi (Technopreneurship) dan Peranan Society 5.0 dalam Perspektif Ilmu Pendidikan Kewirausahaan
}

\author{
Arief Yanto Rukmana ${ }^{1}$, Budi Harto ${ }^{2}$, Hendra Gunawan ${ }^{3}$ \\ ${ }^{1}$ Sekolah Tinggi Ilmu Ekonomi STAN IM, Jl. Jakarta No.79 Bandung \\ ${ }^{2}$ Politeknik LP3I, Bandung \\ ${ }^{3}$ Sekolah Tinggi Manajemen Informatika dan Komputer, Jl. Jakarta No.79 Bandung \\ Email : ariefyantorukmana@gmail.com ${ }^{1}$, budieto@plb.ac.id ${ }^{2}$, hendra@stmik-im.ac.id ${ }^{3}$
}

\begin{abstract}
ABSTRAK
Penelitian ini berupaya mengkaji tentang kajian deskripsi dari proses bisnis (entrepreneur) dengan menggunakan basis teknologi (Technopreneurship) dilihat dari aspek perspektif pendidikan kewirausahaan. Secara deskripsi penelitian ini akan memberikan gambaran tentang ber-entrepreneur serta usaha kecil menengah dengan menggunakan teknologi. Dari segala sudut pandang, baik motivasi, kepemilikan, manajerial, ketenagakerjaan, dan sebagainya Technopreneurship dapat diedukasi melalui dunia pendidikan sebagai dunia transformasi, yaitu ilmu mengembangkan kewirausahaan dengan menggunakan basis teknologi sebagai dasar berwirausaha. Teknoprenuership merupakan pengembangan dari konsep kewirausahaan. Wirausaha adalah salah satu jawaban untuk menjawab ketimpangan antara pertumbuhan penduduk usia produktif dengan ketersediaan lapangan pekerjaan. Dunia pendidikan berkewajiban untuk dapat mencetak generasi - generasi yang memiliki kemandirian, termasuk kemandirian secara ekonomi. Sekolah, kampus juga media pendidikan informal lainnya bukan hanya berfungsi untuk berbagi ilmu dengan teori - teorinya maupun ketrampilan dengan praktek - prakteknya. Namun jika dikaitkan dengan masih rendahnya pemahaman dan minat tentang dunia wirausaha, dunia pendidikan dapat difungsikan juga sebagai media informasi untuk meningkatakan pemahaman dan minat anak didiknya pada dunia kewirausahaan. Mengkomunikasikan pentingnya teknologi dalam pengembangan entrepreneur menjadi tantangan dalam dunia pendidikan. Kajian ini diharapkan bisa menjadi rujukan dalam pengembangan pendidikan kewirausahaan. Paper ini merupakan sebuah konseptual paper yang bersumber dari data sekunder yang berasal dari publikasi terkait tema paper dan bertujuan untuk menggambarkan pentingnya mengenalkan Technopreneurship dan Society 5.0 melalui dunia pendidikan.
\end{abstract}

Kata Kunci: Technopreneurship, Society 5.0, dan pendidikan kewirausahaan

\begin{abstract}
This study seeks to examine the description of the business process (entrepreneur) using the basis of Technology (Technopreneurship) from the perspective of entrepreneurship education. In the description of this research will provide an overview of entrepreneurship and small and medium enterprises using Technology. From all points of view, both motivation, ownership, managerial, employment, and so on, Technopreneurship can be educated through the world of education as a world of transformation, namely the science of developing entrepreneurship using the basis of
\end{abstract}


Technology as a basis for entrepreneurship. Technopreneurship is a development of the entrepreneurial concept. Entrepreneurship is one of the answers to answering the disparity between the growth of the productive age population and the availability of job opportunities. The world of education is obliged to be able to produce generations that have independence, including economic independence. Schools, campuses as well as other informal educational media not only serve to share knowledge with theories and skills with practice. However, if it is associated with the lack of understanding and interest in the world of entrepreneurship, the world of education can also function as an information medium to increase students' understanding and interest in the world of entrepreneurship. Communicating the importance of Technology in entrepreneur development is a challenge in the world of education. This study is expected to be a reference in developing entrepreneurship education. This paper is a conceptual paper sourced from secondary data from publications related to the theme of the paper and aims to illustrate the importance of introducing Technopreneurship and Society 5.0 through the world of education.

Keywords: Technopreneurship, Society 5.0, and entrepreneurship education

\section{PENDAHULUAN}

Perkembangan zaman menuntut manusia untuk terus beradaptasi dengan perubahan untuk penyesuaian dalam kehidupan. Salah satunya adalah dalam bidang ketenagakerjaan. Dewasa ini permasalahan ketenagakerjaan secara langsung maupun tidak langsung salah satunya adalah karena meningkatnya jumlah angkatan kerja dalam waktu yang cepat dan jumlah yang tinggi, sementara kesempatan kerja yang tersedia sangat terbatas akan menyebabkan timbulnya pengangguran. Hal ini akan berkaitan dengan masalah - masalah lainnya seperti ketidakmerataan pendapatan, kemiskinan, perlambatan pertumbuhan ekonomi, urbanisasi, dan instabilitas politik.

Semua ini secara intuitif tampaknya telah dipahami oleh para pengambil kebijakan. Oleh karena itu, berbagai upaya terus dilakukan pemerintah dalam rangka meningkatkan kesempatan kerja untuk mengurangi jumlah pengangguran yang berimplikasi terhadap lambatnya laju pertumbuhan ekonomi, mengingat semakin meningkatnya jumlah angkatan kerja baru yang memasuki pasar kerja.

Penciptaan wirausaha (entrepreneur) menjadi alternatif solusi atas berbagai masalah di masyarakat seperti kemiskinan dan kesenjangan sosial, meningkatnya pengangguran usia produktif dan menipisnya cadangan pasokan energi, yang kesemuanya menuntut adanya tindakan kreatif dan inovatif. Jiwa kewirausahaan bukan hanya sebatas kecerdasan akademik dan keterampilan menghasilkan produk tetapi juga jiwa dinamis dalam menangkap tantangan dan resiko kemudian mengubahnya menjadi 
peluang dan potensi pertumbuhan (Soegoto 2009), dalam (Herwin Mopangga, 2015). Lebih lanjut dikemukakan bahwa entrepreneur mulai berkembang bukan hanya berdasarkan pada imitasi belaka, melainkan sudah mengikuti pada tiga tahapan spektrum, yaitu spectrum invensi, inovasi serta imitasi. Spektrum invensi merupakan tataran entrepreneur yang paling tinggi, setelah inovasi dan imitasi dimana pada spectrum imitasi pelaku bisnis hanya mendasarkan pada meniru produk atau bisnis yang sudah ada untuk mendapatkan bagian pasar dari produk tersebut. Sementara spectrum inovasi dimaknai sebagai kegiatan ber-entrepreneur dengan sentuhan-sentuhan perubahan pada berbagai aspek, sehingga menimbulkan nilai baru. Bahkan pandangan yang dikemukakan (Bryd \& Brown, 2003) bahwa inovasi bisa dilakukan secara incremental maupun radikal. Spektrum akhir adalah invention atau menemukan sesuatu yang baru yang benar-benar belum diketemukan.

Untuk meningkatkan minat berwirausaha/entrepreneur salah satunya adalah dengan meningkatkan pemahaman dan minat masyarakat terhadap bidang bidang kewirausahaan menurut (A.Rukmana \& T.Sukanta, 2019). Kegiatan wirausaha harus didorong dengan keberanian dan keuletan serta tekad yang kuat, karena berwirausaha pada dasarnya berhimpitan dengan ketidakpastian, dalam hal keberhasilan maupun kegagalan. Karena hanya dengan menggeluti usaha secara penuh keberanian dan beresiko tinggi maka usaha akan tumbuh berkembang.

Seiring berjalannya waktu, pertumbuhan kewirausahaan juga didukung dengan pengembangan teknologi yang semakin baik. Sehingga telah banyak entrepreneur muda yang mulai menggunakan teknologi dalam usaha mereka. Penggabungan kedua hal ini membangun suatu istilah baru dalam dunia kewirausahaan yaitu Technopreneurship. Beberapa tahun terakhir ini konsep Technopreneurship menjadi sangat popular di banyak kalangan, dibahas dalam banyak forum, dan dikembangkan di banyak negara dengan dukungan penuh dari pemerintah. Sebagai contoh Finlandia salah satu negara yang berhasil dalam pengembangan Knowledge Based Economy. Sebelum era tahun 90an, negara ini mengandalkan sumber daya alam sebagai penggerak utama ekonomi. Mulai di awal tahun 90-an sejalan dengan berkembangnya teknologi komunikasi, Finlandia beralih ke bisnis teknologi. Hal tersebut ditandai dengan revolusi bisnis yang dilakukan oleh perusahaan lokalnegara tersebut yang bernama Nokia. Perusahaan yang awal mulanya adalah perusahaan kayu yang memproduksi kayu lapis. Kini telah 
menjadi salah satu produsen mobile-phone raksasa dunia.

Technopreneur salah satu bagian dari perkembangan berwirausaha (entrepreneur) memberikan gambaran berwirausaha dengan menggunakan inovasi basis Technology. Konsep Technopreneur didasarkan pada basis tekhnologi yang dijadikan sebagai alat berwirausaha, misalnya munculnya bisnis aplikasi online, bisnis security system, dsb.

Technopreneurship berasal dari gabungan kata "Technology" dan "entrepreneurship". (Depositario, et al., 2011). Technopreneurship merupakan proses sinergi dari kemampuan yang kuat pada penguasaan teknologi serta pemahaman menyeluruh tentang konsep kewirausahaan (Sosrowinarsidiono, 2010). Sudarsih dalam Prosiding KNIT RAMP-IPB (2013:57) mengemukakan bahwa Technopreneurship adalah proses dan pembentukan usaha baru yang melibatkan teknologi sebagai basisnya dengan harapan bahwa penciptaan strategi dan inovasi yang tepat kelak bisa menempatkan teknologi sebagai salah satu faktor untuk pengembangan ekonomi nasional. Pendapat lainnya menyebutkan bahwa Technopreneurship adalah proses dalam sebuah organisasi yang mengutamakan inovasi dan secara terus menerus menemukan problem utama organisasi, memecahkan permasalahannya, dan mengimplementasikan cara-cara pemecahan masalah dalam rangka meningkatakan daya saing di pasar global (Okorie, 2014). Dari pandangan-pandangan diatas maka Technopreneurship pada intinya akan menggabungkan antara teknologi dan kewirausahaan.

Melalui penggalakan pendidikan di bidang kewirausahaan di tengah perkembangan Society 5.0 dimana semua berbasis teknologi internet, kini teknologi menjadi bagian sangat penting yang tak terpisahkan bagi kehidupan manusia atau masyarakat baik untuk pendidikan, bersosialisasi ataupun berbisnis melalui layanan internet yang saat ini sangat mendorong tingginya pertumbuhan ekonomi (Rojko, Andreja. 2017). diharapkan dapat meningkatakan pemahaman dan minat masyarakat dalam dunia entrepreneur sehingga dapat meningkatkan jumlah wirausaha di Indonesia dan akan menciptakan peluang-peluang kerja serta akan dapat mengurangi jumlah pengangguran dan permasalahan terkait hal tersebut.

(Warhuus, 2014 ) berpendapat bahwa pendidikan dapat mengatasi kurangnya kemampuan kewirausahaan yang dirasakan di negara-negara yang dapat menghasilkan lebih banyak individu wirausaha yang banyak mengeksploitasi tingkat tinggi peluang 
wirausaha yang dirasakan. Penelitian sebelumnya (Astuti, 2018) menyebutkan bahwa pendidikan kewirausahaan berpengaruh positif dan signifikan terhadap minat berwirausaha. Kemudian Penelitian (Rifai, 2016) menyebutkan bahwa terdapat pengaruh positif dan signifikan pendidikan kewirausahaan terhadap minat berwirausaha. Selanjutnya penelitian (Arief Y Rukmana, 2017) juga menyebutkan bahwa terdapat pengaruh positif dan signifikan pendidikan kewirausahaan terhadap niat dan sikap berwirausaha. Namun pada penelitian (Nurikasari, 2016) hasil penelitian menunjukkan bahwa tidak terdapat pengaruh yang signifikan pendidikan kewirausahaan terhadap minat berwirausaha.

Meskipun dalam pelaksanaanya masih belum muncul ide-ide usaha yang berbasis teknologi baru, namun program pembelajaran telah membuka wawasan mahasiswa mengenai konsep Technopreneurahip sekaligus memotivasi mahasiswa untuk berwirausaha. Program pendidikan kewirausahaan membutuhkan usaha pengembangan dan dukungan terus menerus agar budaya Technopreneurship tercipta di kalangan mahasiswa (Nurseto, 2010)

Dengan melakukan kajian terhadap peraturan dan kebijakan terkait kewirausahaan dan perkembangan pendidikan di Indonesia serta fakta - fakta yang berasal dari data sekunder yang berasal dari instansi tekait, tulisan ini diharapkan dapat menjadi sebuah gambaran tentang pentingnya Technopreneurship melalui dunia pendidikan.

\section{METODE PENELITIAN}

Metodologi pada penulisan ini menggunakan metode deskriptif, yaitu memberikan gambaran tentang fenomena tertentu atau aspek kehidupan tertentu dari masyarakat yang diteliti pada saat ini. Metode deskriptif tidak hanya terbatas pada pengumpulan data, tetapi meliputi analisis dan interprestasi tentang arti data itu. Penelitian deskriptif membandingkan persamaan dan perbedaan fenomena tertentu. 


\section{HASIL DAN PEMBAHASAN}

a. Enterpreneurship dan Teknologi Entrepreneurship adalah proses mengorganisasi dan mengelola risiko untuk sebuah bisnis baru. (Ono Suparno, dkk, 2008) dalam (Estiningsih, Wening. Zainal, Arifin, 2014),. Seorang entrepreneur melakukan hal-hal sebagai berikut :

a. Mengidentifikasi dan mengevaluasi peluang pasar.

b. Menemukan solusi-solusi untuk mengisi peluang pasar tersebut.

c. Memperoleh sumberdaya yang diperlukan (uang, orang, dan peralatan) untuk menjalankan bisnis.

d. Mengelola sumberdaya dari tahap awal (start-up) ke fase bertahan (survival) dan fase pengembangan (ekspansi).

e. Mengelola risiko-risiko yang berhubungan dengan bisnisnya.

Teknologi merupakan bagian dari solusi yang diperlukan untuk memenuhi peluang. Jadi teknologi hanya salah satu dari lima aspek entrepreneurship yang diperlukan. Teknologi bukan lah segalanya dalam Technopreneurship. (Ono, 2008) dalam (Estiningsih dan Zaenal, 2014), menyatakan ada dua hal penting yang harus diperhatikan untuk mendefinisikan Technopreneurship (Technology entrepreneurship), yaitu penelitian dan komersialisasi. Penelitian merupakan penemuan dan penambahan pada ilmu pengetahuan. Komersialisasi dapat didefinisikan sebagai pemindahan hasil penelitian atau teknologi dari laboratorium ke pasar dengan cara yang menguntungkan. Ada sejumlah jalan untuk mengkomersialisasi teknologi, yakni: lisensi, berpartner, atau menjualnya kepada pihak lain yang akan mengkomersialisasikannya.

Teknologi merupakan cara atau metode untuk mengolah sesuatu agar terjadi efisiensi biaya dan waktu, sehingga dapat menghasilkan produk yang lebih berkualitas. Dasar-dasar penciptaan tekologi adalah: kebutuhan pasar, solusi atas permasalahan, aplikasi berbagai bidang keilmuan, perbaikan efektivitas dan efisiensi produksi, serta modernisasi. 


\section{b. Technopreneurship dan konvensional Entrepreneurship}

Menurut (Ono, 2008) dalam (Estiningsih dan Zaenal 2014), teknologi merupakan bagian dari solusi yang diperlukan untuk memenuhi peluang. Jadi teknologi hanya salah satu dari lima aspek entrepreneurship yang diperlukan. Teknologi bukan lah segalanya dalam Technopreneurship.

(Ono, 2008) dalam (Estiningsih dan Zaenal 2014), menyatakan ada dua hal penting yang harus diperhatikan untuk mendefinisikan Technopreneurship (Technology entrepreneurship), yaitu penelitian dan komersialisasi. Penelitian merupakan penemuan dan penambahan pada ilmu pengetahuan. Komersialisasi dapat didefinisikan sebagai pemindahan hasil penelitian atau teknologi dari laboratorium ke pasar dengan cara yang menguntungkan. Ada sejumlah jalan untuk mengkomersialisasi teknologi, yakni: lisensi, berpartner, atau menjualnya kepada pihak lain yang akan mengkomersialisasikannya.

Teknologi merupakan cara atau metode untuk mengolah sesuatu agar terjadi efisiensi biaya dan waktu, sehingga dapat menghasilkan produk yang lebih berkualitas. Dasar-dasar penciptaan tekologi adalah: kebutuhan pasar, solusi atas permasalahan, aplikasi berbagai bidang keilmuan, perbaikan efektivitas dan efisiensi produksi, serta modernisasi.

Terdapat perbedaan antara entrepreneurship biasa dan Technopreneurship (Technology entrepreneurship). Technology entrepreneurship harus sukses pada dua tugas utama, yakni: menjamin bahwa teknologi berfungsi sesuai kebutuhan target pelanggan, dan teknologi tersebut dapat dijual dengan mendapatkan keuntungan (profit). Entrepreneurship biasa umumnya hanya berhubungan dengan bagian yang kedua, yakni menjual dengan mendapatkan profit.

Secara umum, ada dua jenis bisnis yang dapat membentuk Technology entrepreneur (Technopreneur), yakni: bisnis lifestyle dan bisnis pertumbuhan tinggi (high growth businesses). Bisnis lifestyle adalah suatu usaha yang umumnya tidak tumbuh dengan cepat. Bisnis seperti ini biasanya tidak menarik bagi investor profesional seperti angel investor atau pemodal ventura (venture capitalist). Bisnis tersebut tidak mempunyai potensi yang cukup untuk menghasilkan kekayaan yang signifikan. Seseorang mungkin ingin menjadi bos sendiri, mengatur jadwal sendiri, dan ingin memiliki kendali yang lebih besar. 
Jenis bisnis yang lain adalah bisnis pertumbuhan tinggi. Bisnis pertumbuhan tinggi memiliki potensi untuk menghasilkan kekayaan yang besar dengan cepat. Jenis bisnis ini umumnya berisiko tinggi namun juga memberikan imbalan yang tinggi, sehingga menarik bagi pemodal ventura (venture capitalists). Contohcontoh perusahaan dengan bisnis petumbuhan tinggi adalah: Dell, Genzyme, EMC, Amgen, dan Biogen-Idec.

\section{c. Perkembangan Dunia Pendidikan Di Indonesia}

Pendidikan merupakan hal penting bagi agenda pembangunan Pemerintah Indonesia. Salah satu tema kebijakan fiskal dalam RAPBN 2020 yaitu penguatan kualitas untuk mewujudkan SDM yang sehat, cerdas, terampil, dan sejahtera. Belanja pendidikan telah meningkat secara signifikan di tahun-tahun terakhir setelah terjadinya krisis ekonomi. Secara nyata, belanja pendidikan meningkat dari tahun 2018 sampai 2020. Di tahun 2020 Anggaran Pendapatan dan Belanja Negara (APBN) Tahun Anggaran 2020 menyebutkan anggaran pendidikan pada 2020 sebesar Rp 505,8 triliun. Angka ini meningkat 2,7\% dari tahun sebelumnya yang sebesar Rp 492,5 triliun. peningkatan pada 2019 mencapai 11,3\%, jumlah ini setara dengan jumlah di negara lain yang sebanding (Kemendiknas).

Tabel 1. Data pendidikan penduduk 15 tahun ke atas

\begin{tabular}{llll}
\hline $\begin{array}{l}\text { Pendidikan yang } \\
\begin{array}{l}\text { Ditamatkan Penduduk 15 } \\
\text { Tahun ke Atas }\end{array}\end{array}$ & $\begin{array}{l}\text { Tahun } \\
\text { Tidak/belum sekolah }\end{array}$ & $\begin{array}{l}\text { Tahun } \\
2019\end{array}$ & $\begin{array}{l}\text { Tahun } \\
2020\end{array}$ \\
\hline Tidak tamat SD & 51,91 & 59,20 & 59,62 \\
\hline SD/sederajat & 65,40 & 64,39 & 64,05 \\
\hline SMP/sederajat & 69,65 & 69,22 & 69,62 \\
\hline SM+/sederajat & 55,55 & 55,46 & 57,03 \\
\hline Akademi/Diploma & 68,18 & 68,03 & 67,18 \\
\hline Universitas & 75,87 & 76,23 & 76,07 \\
\hline
\end{tabular}

Sumber : BPS Indonesia (2020)

Membangun keutuhan bangsa melalui pendidikan dilakukan melalui upaya mencerdaskan kehidupan bangsa. Esensi mencerdaskan kehidupan bangsa yang diamanatkan dalam Pembukaan UUD 1945 dan menjadi domain utama 
pendidikan adalah membangun bangsa Indonesia yang berakar pada budaya, dengan segala keragamannya, untuk menjadi manusia Indonesia yang beriman dan bertakwa kepada Tuhan Yang Maha Esa, demokratis, berkarakter, mandiri, berdaya saing, dan berdaya tahan kuat di dalam percaturan hidup antar bangsa yang ditopang oleh penguasaan ilmu pengetahuan, teknologi, dan seni yang terarah kepada peningkatan taraf hidup dan kesejahteraan masyrakat (Kartadinata, 2019).

\section{d. Pendidikan Kewirausahaan di Indonesia}

Pendidikan memiliki peran penting dalam pengembangan manusia seutuhnya dan pembangunan masyarakat Indonesia seluruhnya. Pengembangan manusia harus dilakukan secara utuh, yang mencakup pengembangan daya pikir, daya qolbu, daya fisik, dan penguasaan ilmu pengetahuan, teknologi, seni serta olahraga (Slamet, 2011). Selain itu, pengembangan manusia juga diharapkan menghasilkan manusia yang mampu dan sanggup berperan aktif dalam membangun masyarakat Indonesia seluruhnya.

Tugas sekor pendidikan baik formal maupun informal bukan hanya mencetak manusia - manusia yang berpendidikan, tetapi secara lebih luas lagi, sektor pendidikan harus mampu menciptakan manusia - manusia yang mandiri (Estiningsih dan Zaenal, 2014). Dengan kenyataan bahwa tidak semua penduduk Indonesia usia produkif dan tergolong sebagai angkatan kerja dapat terserap didunia kerja, maka sektor pendidikan bertanggungjawab untuk mencari solusi, bagaimana agar output yang dihasilkan tidak hanya berorientasi untuk menjadi pekerja, disisi peran sektor pendidikan untuk memperkenalkan dan memotivasi anak didiknya agar memahami bahwa selain menjadi seorang pekerja ternyata bidang wirausaha juga menjadi bidang yang cukup menjanjikan untuk didalami.

\section{e. Technopreneur dan Pendidikan}

Pendidikan memiliki peran penting dalam pengembangan manusia seutuhnya dan pembangunan masyarakat Indonesia seluruhnya. Pengembangan manusia harus dilakukan secara utuh yang mencakup pengembangan daya pikir, daya 
qolbu, daya fisik, dan penguasaan ilmu pengetahuan, teknologi, seni serta olahraga (Slamet, 2011). Selain itu, pengembangan manusia juga diharapkan menghasilkan manusia yang mampu dan sanggup berperan aktif dalam membangun masyarakat Indonesia seluruhnya. Tugas sekor pendidikan baik formal maupun informal bukan hanya mencetak manusia - manusia yang berpendidikan, tetapi secara lebih luas lagi, sektor pendidikan harus mampu menciptakan manusia - manusia yang mandiri. Dengan kenyataan bahwa tidak semua penduduk Indonesia usia produkif dan tergolong sebagai angkatan kerja dapat terserap didunia kerja, maka sektor pendidikan bertanggungjawab untuk mencari solusi, bagaimana agar output yang dihasilkan tidak hanya berorientasi untuk menjadi pekerja, disisi peran sektor pendidikan untuk memperkenalkan dan memotivasi anak didiknya agar memahami bahwa selain menjadi seorang pekerja ternyata bidang wirausaha juga menjadi bidang yang cukup memjanjikan untuk didalami (Putri, 2013).

\section{f. Link and Match Dunia Industri dan Pendidikan}

Terbentuknya kerja sama yang erat antara dunia pendidikan dan dunia usaha atau industri diharapkan mampu mengisi ruang perbedaan antara teori dan praktek yang di ajarkan di kampus dengan kebutuhan kompetensi sebenarnya di dunia industri.

Perguruan Tinggi harus memiliki berbagai program untuk meningkatkan jiwa inovatif dan semangat Technopreneur, konsep pembelajaran elearning dan meningkatkan digital talent menjadi salah satu upaya mencetak lulusan yang tangguh dan siap menghadapi berbagai era yang terjadi baik era digitalisasi, era revolusi 4.0 maupun era Society 5.0. Dengan pengembangan teknologi dan kecepatan penguasaan informasi, perguruan tinggi dapat meningkatkan tumbuhnya generasi Technopreneur yang mampu memanfaatkan teknologi untuk mentransformasi produk atau jasa yang bias memiliki nilai tinggi dan keekonomian. 


\section{g. Society 5.0}

Implementasi dari Society 5.0 ini meliputi pengolahan data yang masif di ruang maya (cyberspace) yang dikumpulkan dari aktivitas manusia dan benda-benda fisik lainnya. Hasil olahan tersebut akan menjadi dasar dalam keputusan yang menciptakan efisiensi, keamanan, kenyamanan, kesehatan, serta distribusi kesejahteraan yang lebih berimbang.

diharapkan sumber daya manusia saat ini memiliki jiwa Technopreneur yakni gabungan dari dua bidang yaitu Technology dan Entrepreneur sehingga bisa maknai bahwa Technopreneur diartikan sebagai suatu peluang usaha dengan memanfaatkan kemajuan teknologi yang ada saat ini, kecanggihan teknologi yang tak pernah berhenti berkembang seiring berjalannya waktu yang mau tidak mau memaksa banyak negara-negara maju dan berkembang turut melakukan berbagai perubahan yang mampu beradaptasi memasuki Era Society 5.0 yang kini dipelopori oleh Negara Jepang.

Konsep Society 5.0 merupakan sebuah penyempurnaan dari konsep sebelumnya yakni Society 1.0, Society 2.0, Society 3.0 dan Society 4, dimana pada Society 1 manusia masih berada di era yang terbelakang yakni era berburu dan baru mengenal tulisan. Selanjutnya pada Society 2.0 adalah suatu era yang lebih maju yakni pertanian dimana manusia sudah mulai mengenal bertani dan bercocok tanam dan pada Society 3.0 sudah memasuki era industri yakni saat masyarakat sudah mulai menggunakan bantuan alat atau mesin untuk menunjang aktivitas sehari-hari dan selanjutnya yang terkini adalah Society 4.0 yang telah mengenalkan masyarakat terhadap program Computer hingga Internet dalam kehidupan sehari-hari. Perubahan selanjutnya yang saat ini terjadi adalah telah hadir Era Society 5.0 yakni era dimana semua berbasis teknologi internet, kini teknologi menjadi bagian sangat penting yang tak terpisahkan bagi kehidupan manusia atau masyarakat baik untuk pendidikan, bersosialisasi ataupun berbisnis melalui layanan internet yang saat ini sangat mendorong tingginya pertumbuhan ekonomi.

Revolusi Industri 4.0 dan Society 5.0 menurut (Andreja 2017:80) merupakan gerakan nyata terhadap perkembangan informasi dan teknologi yang semakin canggih. Kedua revolusi tersebut sebenarnya memiliki esensi yang berbeda, 
akan tetapi dengan core yang sama yaitu teknologi. Pertama adalah industri 4.0 merupakan industri yang menggabungkan teknologi otomatisasi dengan teknologi cyber. Ini merupakan tren otomatisasi dan pertukaran data dalam teknologi manufaktur. Ini termasuk sistem cyber-fisik, Internet of Things (IoT), komputasi awan dan komputasi kognitif. Menurut (Agustini 2018:6) Revolusi indutri 4.0 juga disebut sebagai revolusi industri yang akan mengubah pola dan relasi antara manusia dengan mesin. Inovasi yang diawali dengan besarnya data di internet dan penggunaan cloud mengubah produk industri. Serta mengubah proses produksi dan pemasaran produk. Bahkan mengubah gaya hidup masyarakat karena produk dari revolusi industri ini dapat dilihat penggunaannya di kehidupan sehari-hari. Secara umum revolusi industri keempat ditandai dengan full automation, proses digitalisasi, dan penggunaan alat elektronik dengan sistem informatika.

Society 5.0, nilai baru yang diciptakan melalui inovasi akan menghilangkan kesenjangan regional, usia, jenis kelamin, dan bahasa dan memungkinkan penyediaan produk dan layanan yang dirancang secara halus untuk beragam kebutuhan individu dan kebutuhan laten. Dengan cara ini, akan mungkin untuk mencapai masyarakat yang dapat mempromosikan pembangunan ekonomi dan menemukan solusi untuk masalah sosial.

Kedua revolusi tersebut saling berkesinambungan membentuk pola tatanan kehidupan bermasyarakat, yaitu ketika setiap permasalahan dan tantangan yang terdapat didalamnya dapat diselesaikan melalui perpaduan inovasi dari berbagai unsur yang diterapkan pada revolusi industri 4.0 dan kemudian dipadukan dengan Society 5.0. Hubungan tersebut diharapkan dapat berperan aktif dalam meningkatkan kualitas kehidupan sosial, sehingga setiap usaha dalam meningkatkan dan mengembangkan revolusi tersebut akan mencermintkan produk dan layanan masyarakat yang bisa diberikan secara berkelanjutan.

\section{SIMPULAN}

Berdasarkan uraian pada pendahuluan dan pembahasan pendidikan kewirausahaan berbasis teknologi, pemanfaatan teknologi dengan tepat menjadi pondasi utama dalam mengembangkan jiwa dan semangat Technopreneurship. Untuk melahirkan 
entrepreneur-entrepreneur muda sukses tersebut di perlukan kesungguhan dan keseriusan dari perguruan tinggi dalam mengemban misi entrepreneurial campus dalam menyongsong masyarakat ekosistem pintar ( Society 5.0 ). Program-program kewirausahaan yang telah digagas dan dijalankan oleh berbagai perguruan tinggi khususnya di Indonesia, patut kiranya dijadikan sebagai teladan dalam memulai memfokuskan perguruan tinggi dalam melahirkan entrepreneur-entrepreneur muda sukses yang dapat pengintergrasikan konsep wirausaha dan konsep teknologi sehingga dapat meningkatkan potensi pengembangan usaha yang dimilikinya.

Pengembangan kewirausahaan nasional merupakan tugas besar dan mulia yang membutuhkan kebersamaan segenap komponen bangsa. Penumbuhan wirausaha baru tidak bisa dilakukan secara parsial ataupun oleh satu instansi saja, karena masingmasing instansi mempunyai keterbatasan sesuai tugas pokok dan fungsi masingmasing. Program penumbuhan wirausaha baru harus dilakukan secara comprehensive dengan melibatkan seluruh instansi yang terkait baik pemerintah pusat maupun daerah, lembaga pendidikan, badan usaha dan lembaga-lembaga swadaya masyarakat Semangat kebersamaan dan sinergi unsur pemerintah, akademisi, dunia usaha, wirausaha baru dan segenap komponen masyarakat lainnya perlu terus menerus didorong agar lebih banyak anak negeri yang menetapkan pilihan profesi menjadi wirausaha. Dalam rangka pengembangan kewirausahaan nasional yang lebih efektif perlu dipertimbangkan untuk membentuk lembaga koordinasi pengembangan kewirausahaan nasional yang tetap menjaga aspek sinergi dan kebersamaan dari segenap komponen bangsa dengan memberikan akses koordinasi yang lebih terstruktur baik pada dunia pendidikan, teknologi hingga badan- badan kreatif untuk menampung hasil dari Technopreneurship.

Kerjasama yang baik antara peran perguruan tinggi dan pemerintah serta Kolaborasi kelompok komunitas usaha menjadikan Technopreneur akan tumbuh dan berkembang di dalam diri mahasiswa sehingga nantinya akan tercipta lulusan perguruan tinggi yang pakai dan siap berkomptisidi era Society 5.0 


\section{DAFTAR PUSTAKA}

Anata, Firdaus, 2013, Pengaruh Tingkat Pengangguran Terbuka, PDRB Perkapita, Jumlah Penduduk dan Indeks Williamson Terhadap Ttingkat Kriminalitas (Studi pada 31 Propinsi di Indonesia tahun 2007 - 2012), Jurnal Ilmiah Fakultas Ekonomi Dan Bisnis, Universitas Brawijaya, Malang.

Astuti, P., Djaelani, A. Q., \& ABS, M. K. (2018). Pengaruh Pendidikan dan Praktik Kewirausahaan Terhadap Minat Mahasiswa Untuk Berwirausaha (StudiPada Mahasiswa Fakultas Ekonomi dan Bisnis Universitas Islam Malang). E-Jurnal Riset Manajemen: Universitas Islam Malang 7(01).

Badan Pusat Statistik Indonesia. 2020. Statistik Penduduk Berumur 15 Tahun Ke Atas Menurut Pendidikan Tertinggi yang Ditamatkan dan Jenis Kegiatan Selama Seminggu yang Lalu, 2008-2020. Jakarta

Byrd, J \& Brown, P.L. 2003. The innovation equation. building creativity and risk taking in your organization. San Fransisco: Jossey-Bass/Pfeiffer. A wiley imprint. Diakses melalui www.pfeiffer.com

Clelland, David MC. (1961). Entrepreneur Behavior And Characteristics of Entrepreneurs. The Achieving Society.

Depositario, D.P.T., Aquino, N.A., and Feliciano, K.C., 2011, Entrepreneurial Skill Development Needs of Potential Agri-Based Technopreneurs, J. ISSAAS. Vol. 17. No.1:106-120

Direktorat Akademik, Direkturat Jendral Pendidikan Tinggi, Departemen Pendidikan Nasional, 2008. Technopreneurship, Draft Buku Pegangan

Estiningsih, Wening. Zainal, Arifin, H. (2014). Technopreneurship; Challenge For Entrepreneurship Educational Development in Indonesia, Forum Tahunan Pengembangan Iptek Dan Inovasi Nasional IV, LIPI, Tahun 2014.

Kartadinata. (2019). Profesi Keguruan. In Profesi Keguruan dalam Mengembangkan Siswa. Universitas Terbuka, Jakarta, pp. 1-47. (Vol. 53, Issue 9).

Kartadinata, S. (n.d.). No Title. Membangun Keutuhan Bangsa Melalui Pendidikan Dalam Bingkai Utuh Sistem Pendidikan Nasional, Universitas Pendidikan Indonesia, Bandung.

Mopangga, Herwin. 2008. Penerapan Teknologi dan Transformasi Kelembagaan pada Masyarakat Pedesaan di Indonesia. Jurnal Ilmiah Agropolitan, 1(1): 29-39.

Mopangga, Herwin. (2015). Studi Kasus Pengembangan Wirausaha Berbasis Teknologi (Technopreneurship) di Provinsi Gorontalo. TRIKONOMIKA, 14(1), 13. https://doi.org/10.23969/trikonomika.v14i1.587

Nurseto, T., 2010, Pendidikan Berbasis Entrepreneur, Jurnal pendidikan Akuntansi Indonesia, Vol.8, No.2, UNY, Yogyakarta

Okorie N. N. et al. 2014. Technopreneurship: An Urgent Need in The Material World for Sustainability in Nigeria. European Scientific Journal, 10(30): 1857-7881. 
Ono, Suparno et al. 2013. Peningkatan Minat Technopreneurship Melalui Workshop Satu Hari. Prosiding KNIT RAMP-IPB: 131-139.

Putri, Novita Delima, 2013, Pendidikan Kewirausahaan; Sebagai sebuah Tantangan Bagi Pengembangan Pendidikan Indonesia, Prossiding Seminar Nasional: Sustainable Competitive Advantages - 3. Unsoed, Purwokerto.

Rukmana, A. Y., \& Sukanta, T. A. (2020, Mei 1). Analisis Strategi Bersaing dan Strategi Bertahan pada Industri Mikro dan Kecil Panganan Keripik Kemasan di Kecamatan Coblong Kota Bandung Jawa Barat Tahun 2020 Ditengah Situasi Sulit Penyebaran Pandemi COVID-19. Jurnal Sains Manajemen \& Akuntansi, 12(1), 37-53.

Rojko, A. (2017). Industri 4.0 Concept: Background and Overview. ECPE European Center for Power Electronics e.V. Vol. 11. Nuremberg, Germany.

Rifai, I. A., \& Sucihatiningsih, D.W. P. (2016). Pengaruh Pendidikan Kewirausahaan dan Pelaksanaan Kegiatan Business Center Terhadap Minat Berwirausaha Siswa Kelas XI Jurusan Pemasaran SMK Negeri 2 Semarang Tahun Ajaran 2015/2016. Journal of Economic Education, 5 (1): Universitas Negeri Semarang.

Rukmana, A. Y. (2017). Analisis Pengaruh Pembelajaran Di SMK dan Keahlian Kewirausahaan Terhadap Niat Dan Sikap Kewirausahaan Siswa SMK Pelita Bandung (Doctoral dissertation, Tesis Program Magister Management Universitas Widyatama Bandung).

Soegoto, Eddy Soeryanto. 2009. Entrepreneurship; Menjadi Pebisnis Ulung. Jakarta: Elex Media Komputindo.

Sosrowinarsidiono. 2010. Membangun Sinergi Teknologi Dengan Kemampuan Kewirausahaan Guna Menunjang Kemandirian Bangsa. Munas Asosiasi Perguruan Tinggi Ilmu Informatika. Bandung: Politelkom.

Sudarsih, Endang. 2013. Pendidikan Technopreneurship: Meningkatkan Daya Inovasi Mahasiswa Teknik dalam Berbisnis. Prosiding KNIT RAMP-IPB: 56-63.

Sudira, P. (2016). TVET ABAD XXI : filosofi, teori, konsep dan strategi pembelajaran vokasional. D.I.Yogyakarta: UNY Press

Sophia (2016). Study harder? The relationship of achievement goals to attitudes and self-reported use of desirable difficulties in self-regulated learning. Journal of Psychological and Educational Research.

Untari, Dhian Tyas. (2014). Ecopreneurship: Concept Of Responsible Entrepreneurship. Malang: Prosiding 11th International Annual Symposium on Management.

Warhuus, Jan P., (2014). Entrepreneurship Education at Nordic Technical Higher Education Institutions: Comparing and Contrasting Program designs and Content, The International Journal of Management Education. Volume 12, Issue 3. Pagess 317-332. Aarhus University. 
Wiklund, Johan \& Shepherd, Dean. 2005. Entrepreneurial Orientation and Small Business Performance: A Configurational Approach. Journal of Business Venturing, 20(1): 71-91. 